\title{
Impact of point-of-care ultrasound on the hospital length of stay for internal medicine inpatients with cardiopulmonary diagnosis at admission: study protocol of a randomized controlled trial-the IMFCU-1 (Internal Medicine Focused Clinical Ultrasound) study
}

Ximena Cid ${ }^{1,2^{*}}$, David Canty ${ }^{1,3,4}$, Alistair Royse ${ }^{1,5}$, Andrea B. Maier ${ }^{2,6,7}$, Douglas Johnson², Doa El-Ansary ${ }^{1,8}$, Sandy Clarke-Errey ${ }^{9}$, Timothy Fazio ${ }^{10,11}$ and Colin Royse ${ }^{1,4,12}$

\begin{abstract}
Background: Point-of-care ultrasound (POCUS) is emerging as a reliable and valid clinical tool that impacts diagnosis and clinical decision-making as well as timely intervention for optimal patient management. This makes its utility in patients admitted to internal medicine wards attractive. However, there is still an evidence gap in all the medical setting of how its use affects clinical variables such as length of stay, morbidity, and mortality.

Methods/design: A prospective randomized controlled trial assessing the effect of a surface POCUS of the heart, lungs, and femoral and popliteal veins performed by an internal medicine physician during the first $24 \mathrm{~h}$ of patient admission to the unit with a presumptive cardiopulmonary diagnosis. The University of Melbourne iHeartScan, iLungScan, and two-point venous compression protocols are followed to identify left and right ventricular function, significant valvular heart disease, pericardial and pleural effusion, consolidation, pulmonary edema, pneumothorax, and proximal deep venous thrombosis. Patient management is not commanded by the protocol and is at the discretion of the treating team. A total of 250 patients will be recruited at one tertiary hospital. Participants are randomized to receive POCUS or no POCUS. The primary outcome measured will be hospital length of stay. Secondary outcomes include the change in diagnosis and management, 30-day hospital readmission, and healthcare costs.
\end{abstract}

Discussion: This study will evaluate the clinical impact of multi-organ POCUS in internal medicine patients admitted with cardiopulmonary diagnosis on the hospital length of stay. Recruitment of participants commenced in September 2018 and is estimated to be completed by March 2020.

(Continued on next page)

\footnotetext{
* Correspondence: anaite.cid@gmail.com; Ximena.cid@heartweb.com

${ }^{1}$ Department of Surgery, University of Melbourne, Melbourne, VIC, Australia

${ }^{2}$ Department of Medicine and Community Care, Royal Melbourne Hospital,

Parkville, VIC, Australia

Full list of author information is available at the end of the article
}

(c) The Author(s). 2020 Open Access This article is distributed under the terms of the Creative Commons Attribution 4.0 International License (http://creativecommons.org/licenses/by/4.0/), which permits unrestricted use, distribution, and reproduction in any medium, provided you give appropriate credit to the original author(s) and the source, provide a link to the Creative Commons license, and indicate if changes were made. The Creative Commons Public Domain Dedication waiver (http://creativecommons.org/publicdomain/zero/1.0/) applies to the data made available in this article, unless otherwise stated. 
(Continued from previous page)

Trial registration: Australian and New Zealand Clinical Trial Registry, ACTRN12618001442291. Registered on 28 August 2018.

Keywords: Randomized controlled trial, Echocardiography, Focused assessment sonography, Lung ultrasound, Internal medicine

\section{Introduction}

Patients admitted to internal medicine wards with cardiorespiratory symptoms can be difficult to assess and treat as they are usually older, have multiple comorbidities, and take multiple medication. Traditionally, internal medicine physicians rely on the medical history and physical examination, collectively known as the clinical evaluation, to derive a differential diagnosis and formulate an initial management plan. However, it has been reported that clinical evaluation alone is frequently inaccurate in determining the correct diagnosis [1-4]. The delay of making a precise diagnosis and starting an appropriate management could be detrimental for patient outcome. Further management is refined by investigations including medical imaging to confirm or rule out the differential diagnosis. However, unnecessary investigations can be associated with high cost and patient risk such as radiation exposure, contrast-induced nephropathy, and transfer of acutely ill patients to an investigation laboratory.

Ultrasonography has been used in medicine for at least 50 years, is non-invasive and without ionizing radiation. Only in the last two decades have ultrasound machines evolved to produce portable, low-cost units that are readily available for use at the bedside, facilitating its clinical uptake. The terms "clinical ultrasound" and "point-of-care ultrasound" (POCUS) are used to describe a bedside ultrasound examination performed by the treating doctor, as an adjunct to clinical evaluation [5]. Its use has become very common in some medical specialties such as emergency medicine, anesthesia, and critical care. Several prior studies have demonstrated validity and reliability [6-14]. The organ scanned depends on the clinical question. By detecting omitted abnormalities in the physical examination $[1,2,4]$ and improving the hemodynamic status evaluation $[15,16]$, heart POCUS has become a useful tool in the evaluation of undifferentiated shock, guiding resuscitation, or as part of the preoperative evaluation in patients undergoing surgery [17-21] Furthermore, lung ultrasound has proved to be superior than physical examination and chest X-ray diagnosing pneumonia, interstitial syndrome (including pulmonary edema), and pleural effusion [22, 23]. In the emergency department and critical care setting, it is now frequently used in the approach of patients with dyspnea, in which lung POCUS alone or in combination with heart POCUS has demonstrated to be very precise distinguishing the primary cause [24-34].

Studies quantifying clinical impact of POCUS have shown that its use led to change diagnosis and modify management plans in $30 \%-80 \%$ of the cases depending on the clinical scenario [17, 18, 35-38]. Most of these studies have investigated imaging of one particular organ [17, 35, 39-42]. However, a multi-organ approach may better align with the initial assessment of complex cases in internal medicine as they are frequently multi-organ in presentation $[5,43]$. This is especially true among cardiopulmonary patients in which a broad range of differential diagnoses can be proposed [44]. In these patients, a combined heart and lung POCUS can identify the cause of dyspnea in most of the cases or significantly narrow the range of diagnoses [26, 33, 34]. In addition to heart and lung POCUS, lower extremity vein POCUS can be used to accurately identify proximal deep venous thrombosis (DVT) $[12,45]$, which might cause pulmonary embolus and be the cause of shortness of breath or cardiovascular collapse. A multi-organ POCUS of the heart, lungs, and lower extremity veins has already been tested in a randomized trial with respiratory patients from the emergency department, reporting superiority of POCUS to standard diagnostic tests alone for establishing a correct diagnosis within $4 \mathrm{~h}$ [27].

We expect that the addition of a heart, lung, femoral, and popliteal vein POCUS in cardiopulmonary patients admitted to internal medicine wards will have a positive impact in the timely diagnosis formulation and impact on decision-making. Moreover, it is plausible that improving diagnosis and altering management plans may lead to improvement in the workflow and reduction of the length of hospital stay.

\section{Objectives and hypothesis}

The primary aim of the study is to determine whether a heart, lung, and lower extremity vein POCUS reduces the length of hospital stay of patients admitted to internal medicine wards with a cardiopulmonary diagnosis by $>24 \mathrm{~h}$.

The secondary aims are to evaluate the impact of POCUS on: (1) change in diagnosis and management plan; (2) 30-day hospital readmission; and (3) in-hospital health costs. 


\section{Trial design}

The IMFCU-1 trial is a single-center, prospective, randomized, parallel group, unblinded, superiority trial with 1:1 allocation ratio. The intervention is a bedside ultrasound examination, which makes blinding not feasible.

\section{Methods}

Ethics approval for the study was obtained from Melbourne Health Human Research Committee on 27 June 2018 (protocol reference 2018.200). The study has been conducted in accordance with the Declaration of Helsinki and registered with the Australian and New Zealand Clinical Trial Registry on 28 August 2018 (ACTRN12618001442291). Table 1 in shows all the items of the World Health Organization trial registration dataset.

Methods are reported in accordance with the Guidance for protocols of clinical trials (SPIRIT) [46]. The SPIRIT checklist is shown in Additional file 1.

\section{Study setting}

The trial is performed at the Royal Melbourne Hospital $(\mathrm{RMH})$, a tertiary, public, university-affiliated teaching hospital, with 706 beds located in Victoria, Australia. Participants are recruited from the internal medicine wards, which are logistically divided into long-stay and short-stay units containing around 68 and 32 beds, respectively. Approximately $30 \%$ of the internal medicine patients are hospitalized due to cardiopulmonary conditions.

\section{Eligibility criteria}

Patients admitted to the internal medicine ward with a preliminary cardiopulmonary diagnosis are invited to participate in the study. Eligible participants are selected every workday morning by internal medicine physicians during their handover. After presenting the new cases, physicians are asked to identify the cardiopulmonary cases. For the purpose of the study, a cardiopulmonary diagnosis has been defined as a medical suspicion that the main health problem of the patient is related to one of the following heart or lung conditions: heart failure; acute coronary syndrome; pulmonary embolism (PE); pneumonia; decompensated chronic pulmonary obstructive disease; asthmatic crisis; cardiogenic syncope; interstitial pulmonary disease; cardiac valve disease; pleural effusion; or pericardial effusion.

\section{Inclusion criteria}

- Age $\geq 18$ years;

- Less than $24 \mathrm{~h}$ since admission to the internal medicine ward;
- Cardiopulmonary diagnosis defined by an internal medicine specialist.

\section{Exclusion criteria}

- Previous echocardiography during the four weeks before hospital admission;

- Computed tomography chest during the current hospital admission;

- Requiring infectious disease isolation (contact, drops, or respiratory precaution);

- Unable to consent (by themselves or a third person who is nominated/identified as their next of kin).

\section{Intervention}

The intervention is a POCUS performed by an internal medicine physician with previous experience in POCUS and the certification of iHeartScan, iLungScan, and Focused Cardiac Ultrasound courses from the Educational Ultrasound Group of the University of Melbourne (XC).

POCUS is performed with an X-Porte portable ultrasonography machine (Sonosite, Bothwell, Andover, MA, USA) using a $1-5-\mathrm{MHz}$ transthoracic and $6-13-\mathrm{MHz}$ linear ultrasound probes. The ultrasound is performed at the patient's bedside, taking an average of $20 \mathrm{~min}$ to be completed.

Assessment of the heart and lungs is performed based on the iHeartScan and iLungScan protocols designed and validated by the Ultrasound Education Group of the University of Melbourne [47-49]. Heart structure and function are assessed using two-dimensional (2D) images and color flow Doppler; spectral Doppler is not included in this study to facilitate timely completion of the ultrasound and to increase its reproducibility. Heart POCUS involves four anatomical windows to record eight views (Fig. 1): parasternal long axis; right ventricle (RV) inflow; parasternal short axis at the level of the aortic valve; parasternal short axis at the level of the papillary muscle; apical four chambers (A4C); apical five chambers; subcostal four chambers; and subcostal inferior vena cava.

The following variables are assessed and reported: volume and systolic function of the LV and RV; left atrial filling pressure based on the interatrial septum movement; significant regurgitation or stenosis of the valves; presence or absence of pericardial effusion; and diameter and collapsibility of the inferior vena cava. Definitions for each variable abnormality are summarized in Table 2. A final statement about the hemodynamic condition will be written as follows: normal; hypovolemia; vasodilated; primary systolic dysfunction; primary diastolic dysfunction; systolic and diastolic dysfunction; and/or RV dysfunction as described by Royse et al. [15] and summarized in Table 3. 
Table 1 World Health Organization trial registration dataset for IMFCU-1

\begin{tabular}{|c|c|}
\hline Data category & Information \\
\hline Primary registry and trial identifying number & Australian and New Zealand Trial Registration, ACTRN12618001442291 \\
\hline Date of registration & 28 August 2018 \\
\hline Prospective registration & Yes \\
\hline Primary sponsor & Royal Melbourne Hospital \\
\hline Public title & A bedside ultrasound in general medicine patients with cardiopulmonary diagnosis \\
\hline Scientific title & $\begin{array}{l}\text { A randomized trial of focused cardiac, lung, and femoral and vein ultrasound on } \\
\text { the length of stay in internal medicine admissions with a cardiopulmonary diagnosis. } \\
\text { IMFCU-1 study. }\end{array}$ \\
\hline Date of first enrolment & 3 September 2018 \\
\hline Target sample size & 250 \\
\hline Recruiting status & Recruiting (103 recruited) \\
\hline URL & U111112185271 \\
\hline Study type & Interventional \\
\hline Study design & Randomized controlled trial parallel \\
\hline Phase & Not applicable \\
\hline Country of recruitment & Australia \\
\hline Contacts & $\begin{array}{l}\text { Prof Colin Royse (principal investigator) } \\
\text { Address: Level 6, Centre of Medical Research, Royal Parade, Parkville, VIC 3052, Australia. } \\
\text { Telephone: (61)383445673 } \\
\text { Email: colin.royse@heartweb.com } \\
\text { Affiliation: Department of Surgery, University of Melbourne } \\
\text { Department of Anesthesia and Pain Management, Royal Melbourne Hospital }\end{array}$ \\
\hline Key inclusion \& exclusion criteria & $\begin{array}{l}\text { Inclusion criteria: } \\
\text { Adult patients (aged } 18 \text { years or older) admitted to general medicine unit at the Royal } \\
\text { Melbourne Hospital with a cardiopulmonary diagnosis, expected to remain in hospital } \\
\text { longer than } 24 \mathrm{~h} \text {. } \\
\text { Exclusion criteria: } \\
\text { Already admitted longer than } 24 \mathrm{~h} \\
\text { Admitted for social reasons rather than medical } \\
\text { Have received an echocardiography within four weeks before admission or a CT chest } \\
\text { scan during the admission process before enrolment }\end{array}$ \\
\hline Health conditions or problems studied & Heart failure, asthma, COPD, pneumonia, PE, unspecified dyspnea \\
\hline Intervention & $\begin{array}{l}\text { A bedside ultrasound done by a physician trained in POCUS. The ultrasound takes } \\
\text { around } 20 \text { min to be performed. The quality of the report will be assessed by a second } \\
\text { expert who will check the images and videos recorded. }\end{array}$ \\
\hline Primary outcome & LOS at the hospital \\
\hline Secondary outcome & $\begin{array}{l}\text { Incidence of new diagnosis and Incidence of changing management. These two outcomes } \\
\text { will be assessed only in the interventional group. The treating physician will be asked to fill } \\
\text { in a form with the initial diagnosis and plan of management. This form is a checklist } \\
\text { describing further investigations (blood test and imaging), consultation to another specialist } \\
\text { and medication prescribed (diuretics, antibiotics, etc.). After performing and revealing to them } \\
\text { the findings of the bedside ultrasound, the treating physician will be asked to fill a second } \\
\text { form that is exactly the same than the first one. The difference between both will be analyzed } \\
\text { as "change of management" due to our intervention. } \\
\text { Health costs: this outcome will be assessed by the sum of the following three components: } \\
\text { (1) cost per day at the hospital; (2) cost of the pathology investigation; (3) cost of the } \\
\text { imaging tests. }\end{array}$ \\
\hline
\end{tabular}

COPD chronic obstructive pulmonary disease, IMFCU internal medicine focused clinical ultrasound, LOS length of stay, PE pulmonary embolism, POCUS point-of-care ultrasound

The lungs are scanned by division into three anatomical zones as previously reported by Ford et al. [49] (Fig. 2). The anterior zone goes from the sternum edge to the mid-axillary line posteriorly; the upper posterior zone is defined by the mid-axillary line anteriorly, the spinous processes of the thoracic spine posteriorly, and the inferior tip of the scapular inferiorly: and the lower posterior zone is defined by the mid-axillary line anteriorly, the spinous process of the thoracic spine posteriorly, and the inferior rip of the scapula superiorly. 


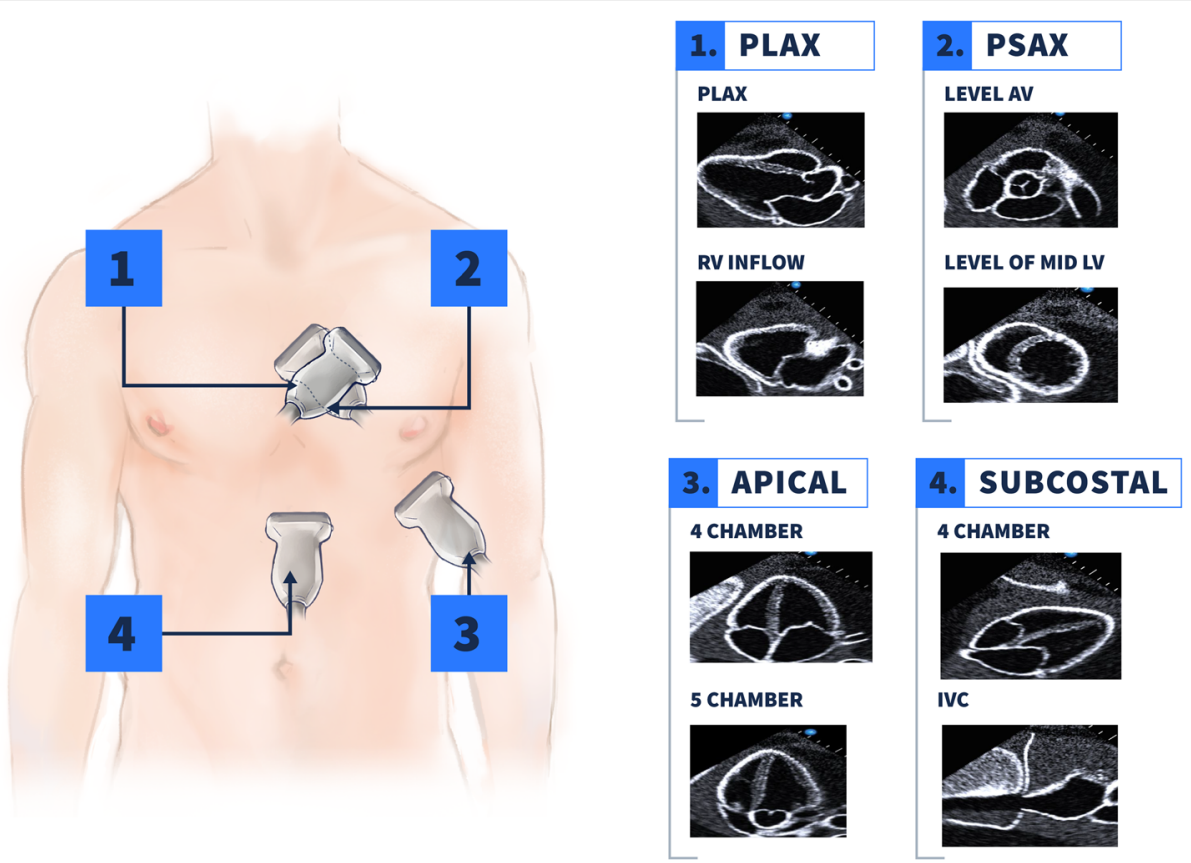

Fig. 1 Ultrasonography windows assessed in heart POCUS. Four anatomical windows are used to assess eight views of the heart: (1) At the level of the fourth intercostal space lateral to the left border of the sternum, PLAX and RV inflow are recorded. (2) The second window is technically the same than the first, from PLAX the probe is rotated in clock direction ending in the PSAX. Two views are recorded at this point, one at the level of the aortic valve and other at the level of papillary muscle or mid left ventricle. (3) Apical window is found about the fifth intercostal space between the mid clavicular line ant the anterior axillary line. In this window the views assessed are A4C and apical five-chamber. (4) Subcostal window involves two views: subcostal four-chamber view of the heart and the IVC view where the IVC can be identified ending in the right atrium. A4C, apical four chambers, IVC inferior vena cava, PLAX parasternal long axis, POCUS point-of-care ultrasound, PSAX parasternal short axis, RV right ventricle

Abnormal findings are recorded as: collapse; consolidation; alveolar/interstitial syndrome; pneumothorax; and/ or pleural effusion. Definitions are described in Table 4. Normal lung pattern is defined as the presence of normal lung sliding, reverberation artefacts from the pleural, and absence of any of the pathologies described.

Femoral and popliteal veins are assessed for intravascular thrombosis using the two-point compression technique [12, 42] (Fig. 3), in which the vein collapsibility is evaluated in two points for each lower extremity: the common femoral vein at the level of the groin and the popliteal vein in the popliteal fossa. A DVT is defined as the inability to completely collapse the vein with the ultrasound probe. This technique has proved a sensitivity of $96.1 \%$ and specificity of $96.6 \%$ diagnosing proximal DVT when it has been compared to standard vein ultrasound performed by radiologists [12, 42].

Once the test has been performed, a structured report summarizing the main findings is written. The quality of this report is immediately assessed by a second POCUS expert reviewing the images recorded. There are three experts participating in this study as quality evaluators (CR, AR, and DV), all of them with at least 10 years of experience in POCUS. The revised report is given to the treating team without any direction of management, who in turn are requested to fill out forms about their clinical assessment before and after receiving the POCUS report (Fig. 4).

The intervention will not be performed or will be stopped after being already started if the patient refers intolerable discomfort during the procedure or in any clinical condition that involves urgent management such as cardiorespiratory arrest, pain, or respiratory distress. In these cases, if some of the variables were already assessed, a report with partial information will be given to the treating team.

The control group follows the standard care pathway, which does not include POCUS. Diagnosis and management will be based on clinical evaluation and other investigations. Ultrasound examinations are not precluded such as those performed by cardiology or radiology staff, but POCUS of the heart, lungs, or lower extremity veins are not allowed during the time that the participant remains admitted to an internal medicine ward.

There are no restrictions in medication use or further standard investigations in any of the two groups. 
Table 2 Variables assessed and definitions of abnormality findings in heart POCUS

\begin{tabular}{|c|c|c|}
\hline & Variable assessed & Definitions \\
\hline LV volume & LVEDD & $\begin{array}{l}\text { Normal LVEDD } 3-5.6 \mathrm{~cm} \\
\text { LV dilated }>5.6 \mathrm{~cm} \\
\text { Hypovolemia }<3 \mathrm{~cm}\end{array}$ \\
\hline \multirow[t]{3}{*}{ LV systolic function } & Overall subjective impression & Normal - Reduced - Increased \\
\hline & $\begin{array}{l}\text { Difference between diameters in diastole } \\
\text { and systole (LVEDD-LVESD) in PLAX view }\end{array}$ & $\begin{array}{l}\text { Normal } 28-44 \mathrm{~mm} \\
\text { Reduced }<28 \mathrm{~mm} \\
\text { Increased }>44 \mathrm{~mm}\end{array}$ \\
\hline & $\begin{array}{l}\text { Difference between areas in diastole and systole } \\
\text { (LVEDA-LVESA) in PSAX view }\end{array}$ & $\begin{array}{l}\text { Normal } 50-65 \mathrm{~mm}^{2} \\
\text { Reduced }<50 \mathrm{~mm}^{2} \\
\text { Increased }>65 \mathrm{~mm}^{2}\end{array}$ \\
\hline \multirow[t]{2}{*}{ RV size } & Compared to LV size & Normal $<2 / 3$ of LV size \\
\hline & RVEDD & $\begin{array}{l}\text { Normal }<4 \mathrm{~cm} \\
\text { Increased }>4 \mathrm{~cm}\end{array}$ \\
\hline RV systolic function & Overall subjective impression & Normal - Decreased \\
\hline \multirow[t]{2}{*}{ LA size } & LA diameter in PLAX or A4C views & Normal $<3.5 \mathrm{~cm}$ \\
\hline & LA area in $A 4 C$ view & $\begin{array}{l}\text { Normal }<20 \mathrm{~cm}^{2} \\
\text { Increased }>20 \mathrm{~cm}^{2}\end{array}$ \\
\hline LA filling pressure & Inter-atrium septum movement & $\begin{array}{l}\text { Normal: systolic reversal of the inter-atrium septum } \\
\text { High filling pressure: fixed curvature of the inter-atrium } \\
\text { septum to the right } \\
\text { Low filling pressure: systolic buckling of the inter-atrium septum }\end{array}$ \\
\hline \multirow[t]{5}{*}{ Cardiac valves } & $\begin{array}{l}\text { Leaflets appearance and thickness } \\
\text { Opening of the valve } \\
\text { Presence of reverse jet }\end{array}$ & $\begin{array}{l}\text { Significant aortic stenosis: } \\
\text { An opening }<1.5 \mathrm{~cm} \text { in PLAX or } \\
\text { Heavy calcification with inability to see the valve opening }\end{array}$ \\
\hline & & $\begin{array}{l}\text { Significant aortic regurgitation: } \\
\text { A jet that runs on the wall of the LV outflow track } \\
\text { A jet that is wider than } 25 \% \text { of the diameter of LVOT } \\
\text { A jet that extends down to the ventricle }>2.5 \mathrm{~cm}\end{array}$ \\
\hline & & $\begin{array}{l}\text { Significant mitral stenosis: } \\
\text { Impaired opening of the mitral valve } \\
\text { A hockey stick appearance of one or both of the mitral leaflets }\end{array}$ \\
\hline & & $\begin{array}{l}\text { Significant mitral regurgitation: } \\
\text { Regurgitation jet covering }>20 \% \text { of the } L A \text { area in A4C or PLAX } \\
\text { A turbulent jet that runs along the wall of the atrium } \\
\text { Prominent flail mitral valve leaflet or rupture papillary muscle }\end{array}$ \\
\hline & & $\begin{array}{l}\text { Significant tricuspid regurgitation: } \\
\text { Any edge-tracking jet } \\
\text { Any central jet }>5 \mathrm{~cm}^{2}\end{array}$ \\
\hline Pericardial effusion & $\begin{array}{l}\text { Presence of anechoic space between parietal } \\
\text { and visceral pericardium }\end{array}$ & Significant pericardial effusion is defined as $>0.5 \mathrm{~cm}$ in any view \\
\hline Inferior vena cava & $\begin{array}{l}\text { Diameter of the inferior vena cava in the } \\
\text { subcostal view during normal breathing }\end{array}$ & $\begin{array}{l}\text { Maximum diameter in } \mathrm{cm} \text { and percentage of collapsibility } \\
\text { during normal inspiration are reported. Estimation of the } \\
\text { right atrium pressure is informed as follows: } \\
\text { IVC }<2.1 \mathrm{~cm} \text { collapsing }>50 \% \rightarrow \text { RAP: } 3 \mathrm{mmHg} \\
\text { IVC }>2.1 \mathrm{~cm} \text { collapsing }<50 \% \rightarrow \text { RAP: } 15 \mathrm{mmHg} \\
\text { Values between the two above } \rightarrow \text { RAP: } 8 \mathrm{mmHg}\end{array}$ \\
\hline
\end{tabular}

$A 4 C$ apical four chambers, $L A$ left atrium, $L V$ left ventricle, $L V E D A$ left ventricle end-diastole area, $L V E D D$ left ventricle end-diastole diameter, $L V E S A$ left ventricle end-systole area, LVESD left ventricle end-systole diameter, PLAX parasternal long axis, POCUS point-of-care ultrasound, PSAX parasternal short axis, RAP right atrium pressure, RVEDD right ventricle end-diastole diameter

\section{Outcomes}

\section{Primary outcome}

The primary outcome is the difference in the median of length of hospital stay between the intervention group and the control group. Length of stay (LOS) is defined as number of hours from admission to the internal medicine ward to hospital discharge.

\section{Secondary outcomes}

Impact on diagnosis and management will be reported as follows: (1) number and proportion of patients in whom a new diagnosis was found with POCUS; (2) number and proportion of patients in whom the main cardiorespiratory diagnosis was changed after POCUS; (3) number and proportion of patients who had a 
Table 3 Hemodynamic state definitions

\begin{tabular}{|c|c|c|c|c|c|c|c|}
\hline & Normal & Hypovolemia & Vasodilated & $\begin{array}{l}\text { Primary systolic } \\
\text { failure }\end{array}$ & $\begin{array}{l}\text { Primary diastolic } \\
\text { failure }\end{array}$ & $\begin{array}{l}\text { Systolic and diastolic } \\
\text { failure }\end{array}$ & RV failure ${ }^{a}$ \\
\hline LV volume & Normal & Decreased & Normal & Increased & Normal/decreased & Increased & RV increased \\
\hline $\begin{array}{l}\text { LV systolic } \\
\text { function }\end{array}$ & Normal & $\begin{array}{l}\text { Normal/ } \\
\text { Decreased }\end{array}$ & Increased & Decreased & Normal & Decreased & $\begin{array}{l}\text { RV } \\
\text { decreased }\end{array}$ \\
\hline LA filling pressure & Normal & Decreased & Normal & Normal & Increased & Increased & Increased \\
\hline
\end{tabular}

Hemodynamic state is defined based on LV volume, LV systolic function, and LA filling pressure

${ }^{a} \mathrm{RV}$ failure can be a hemodynamic state by itself or in combination with LV failure

$L A$ left atrium, $L V$ left ventricle, $R V$ right ventricle

management modification. Management includes adding or removing medications to treat cardiorespiratory conditions (e.g. diuretics), requesting further investigations, and consulting to another specialist.

Readmission to the hospital will be presented as proportion of patients readmitted to the hospital during the next 30 days after hospital discharge in both groups.

Healthcare costs involve total costs spent in each patient during their hospital stay presented in Australian dollars. The data will be organized in several categories (bed stay, imaging tests, pathology investigations). The average cost of each category will be compared between groups.

\section{Participant timeline}

Screening for eligibility, enrolment, allocation, and intervention is performed on the same day (Fig. 5). No follow-up of participants is done after hospital discharge.
Data about LOS, 30-day readmission, and costs will be obtained from the hospital electronic databases after finishing the recruitment.

\section{Sample size}

A sample size of 122 participants in each group has been estimated, which is being rounded up to a total of 250 participants to allow withdrawals. This estimation has been calculated using the statistical software G Power Version 3, based on a t-test of log transformed LOS in hours from internal medicine wards of the RMH (median $103 \mathrm{~h}$ ), a clinically important effect on LOS defined as $\geq 24 \mathrm{~h}$, power of $80 \%$, and alpha of 0.05 .

\section{Recruitment}

One of the investigators (XC) attends every internal medicine handover from Monday to Friday, ensuring
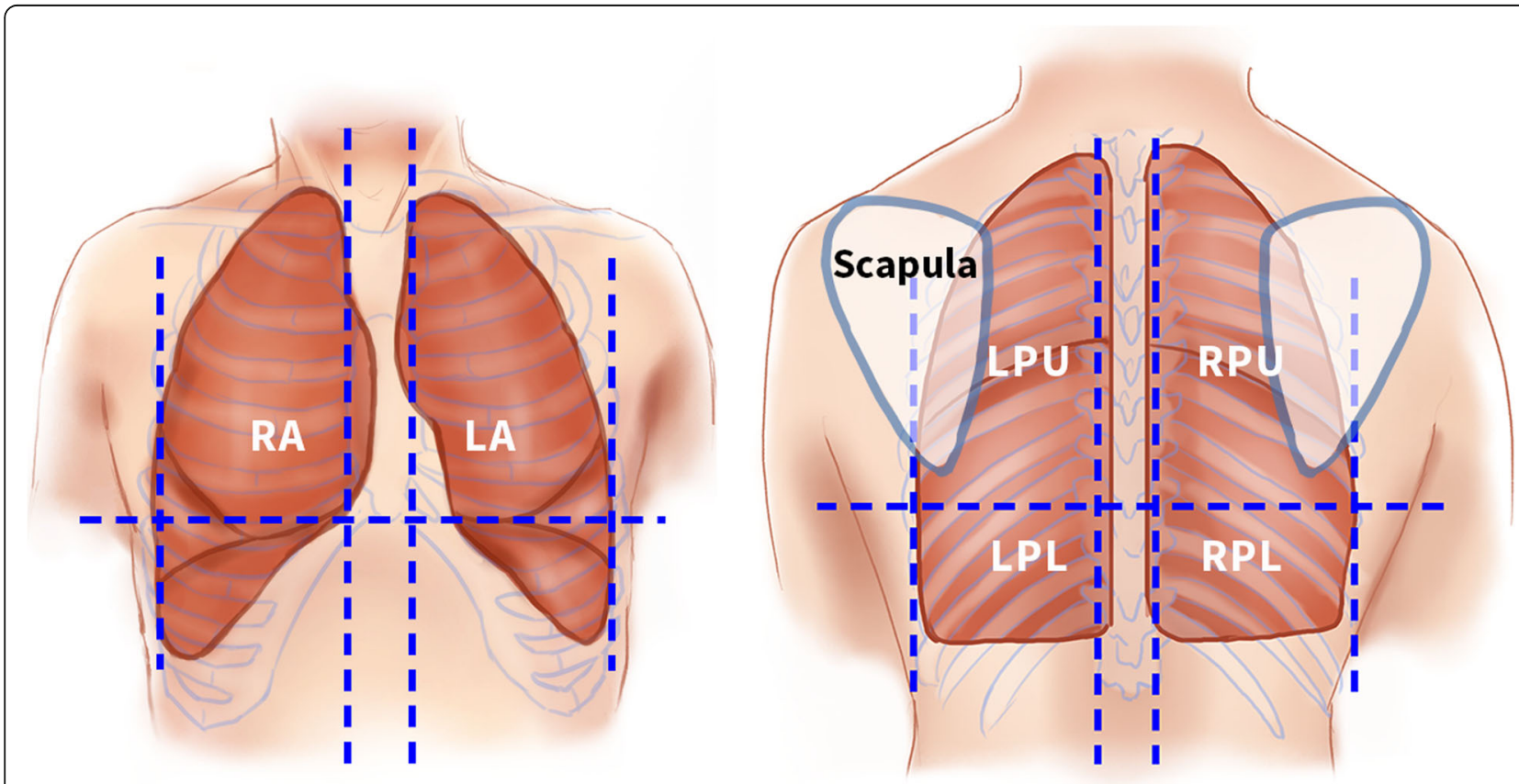

Fig. 2 Anatomical zones scanned in lung POCUS. Illustrations of the front (left) and back (right) of the chest showing the six anatomical zones scanned. LA left anterior, LPL left posterior lower, LPU left posterior upper, POCUS point-of-care ultrasound, RA right anterior, RPL right posterior lower, RPU right posterior upper 
Table 4 Definitions of ultrasound lung abnormalities

\begin{tabular}{ll}
\hline Abnormal lung patterns & Definition / ultrasound findings \\
\hline Alveolar/Interstitial syndrome & $\begin{array}{l}\text { 3 or more B-lines in a single rib space } \\
\text { B-lines were defined as hyperechoic, vertical artifacts arising from the pleural line and } \\
\text { reaching the bottom of the screen without fading } \\
\text { Loss of lung volume, increased tissue density, and hyperechoic static air bronchograms } \\
\text { Consolidation }\end{array}$ \\
$\begin{array}{l}\text { Tissue-like pattern or "hepatization" with minimal volume loss and the presence of dynamic } \\
\text { air bronchograms }\end{array}$ \\
$\begin{array}{l}\text { Absence of lung sliding and lung pulse } \\
\text { Pleural effusion }\end{array}$ \\
$\begin{array}{l}\text { Anechoic space between the parietal and visceral pleura with movement with the respiratory } \\
\text { cycle. Significant pleural effusion is defined as }>1 \mathrm{~cm} \text {. An estimation of the volume of a pleural } \\
\text { effusion in milliters (ml) will be done multiplying by } 200 \text { the distance in cm in the vertical } \\
\text { plane from the diaphragm to the inferior lung border at the junction of the collapsed lung } \\
\text { and aerated lung }\end{array}$ \\
\hline
\end{tabular}

that all the new cardiopulmonary patients from the previous night shift are screened for eligibility. Once the internal medicine physicians have identified the potential participants, the order in which these patients will be approached is done following a randomized sequence created by computer software. In this way, selection bias is significantly reduced. Participants received verbally information and a written document about what it means to participate in this study and how the study is conducted. Once they have agreed to participate, they are asked to sign an informed consent form. In case participants cannot give their consent due to cognitive impairment, a person responsible or a person already stablished as their medical treatment decision maker will be asked to sign the consent on their behalf.

The recruitment rate for the past eight months has been 15 participants per month. Therefore, we expect to complete the recruitment in eight months. A proposed of Consolidated Standard of Reporting Trials (CONSORT) flowchart is shown in Fig. 6.

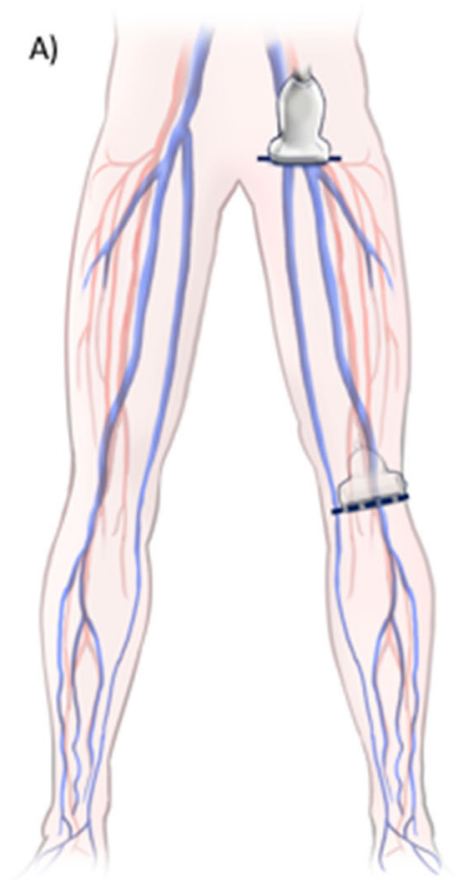

B)

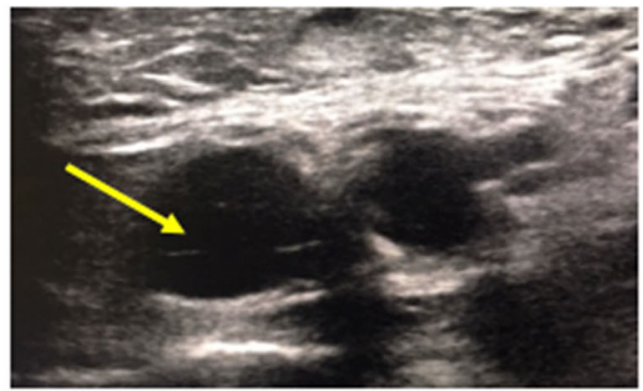

C)

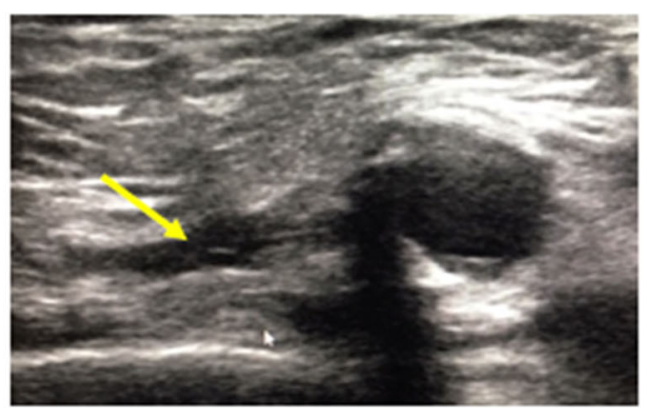

Fig. 3 Femoral and popliteal vein POCUS. a The illustration shows the two points of the lower extremities assessed for DVT: the common femoral vein at the groin level and popliteal vein at the popliteal fossa. b, c Ultrasound images showing the vein marked with yellow arrows before (b) and after (c) external compression has been applied. In this case, the vein is entirely collapsible, consistent with absence of a DVT. DVT deep venous thrombosis, POCUS point-of-care ultrasound 


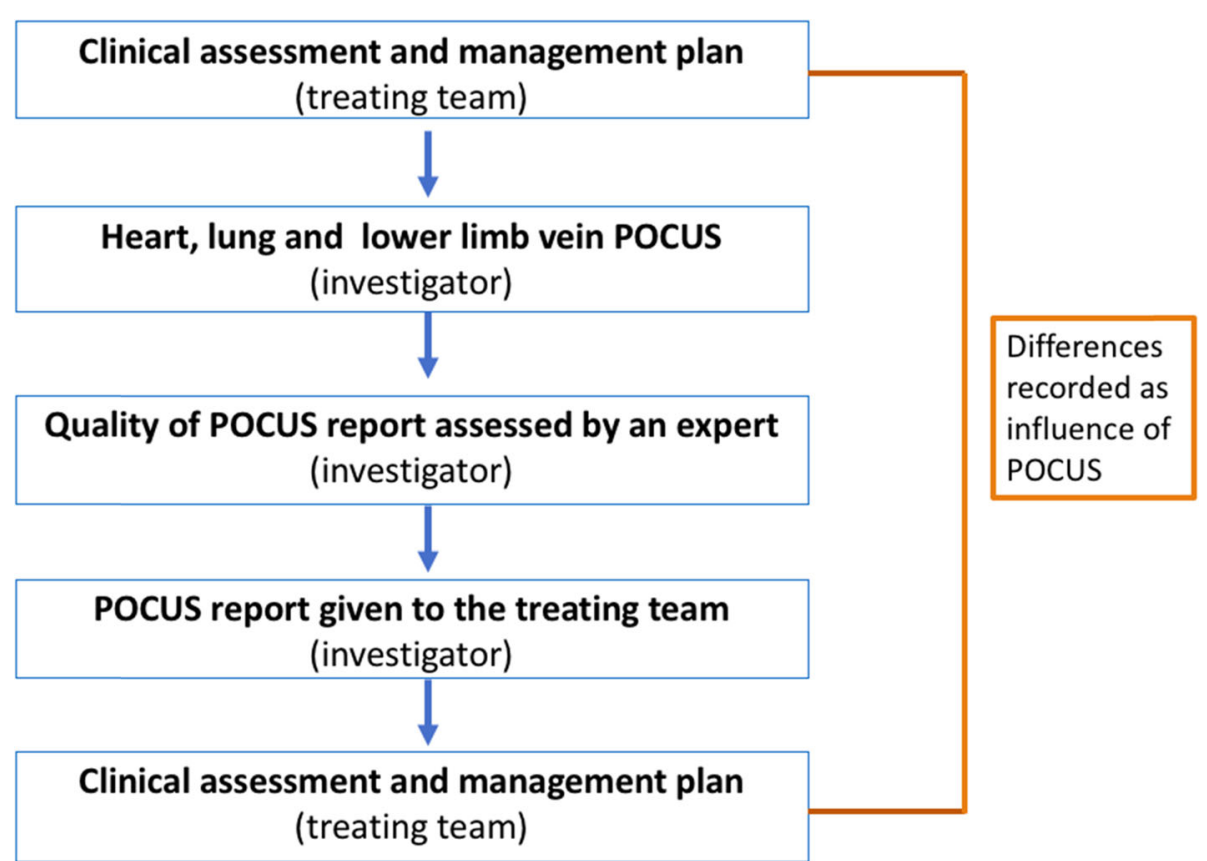

Fig. 4 Steps involved in the intervention group. In the intervention group, a POCUS of the heart, lungs, and femoral and popliteal veins is performed at the patient's bedside. The report summarizing the main findings is assessed by a second expert in POCUS before it is given to the treating team. The treating team is requested to fill out forms about their clinical assessment and management plan before and after receiving the POCUS report. The difference between forms will be recorded as influence of POCUS. POCUS point-of-care ultrasound

\section{Allocation}

Participants are randomly assigned to the intervention or control group with a 1:1 ratio. The allocation sequence is based on permuted blocks of random size, generated by computer software. Blocks sizes are 4,6 , or 8. Sealed, numbered, double-layered, opaque envelopes are used for concealment. The concealment was performed by a non-investigator. Enrolment and allocation will be done by the same investigator after participant has signed the informed consent form. The only person who has access to the allocation sequence is the main investigator, who is not involved in the recruitment process.

\section{Blinding}

Due to the nature of the intervention, blinding was not possible. It was considered unethical to perform POCUS and conceal the results in the control group. However, in order to reduce detection bias, the person assigning the primary outcome will be blinded to what group each participant belongs.

\section{Withdrawal from the study}

If participants withdraw from the study, their data will not be available for analysis. To date this has not occurred and we anticipate a very low withdrawal number.

\section{Data collection methods}

Demographic data and baseline information will be gathered prospectively by one of the investigators from the medical notes. Baseline data is detailed in Table 5.

\section{Primary outcome}

Hospital LOS is obtained from the hospital operating system and is not influenced by any of the investigators. A list with full name, patient number, and the date of admission, but blinded to allocation, will be sent to the hospital Business Intelligence Unit to generate the LOS data.

If patients are transferred from physical internal medicine wards to the "Hospital in the Home" (HITH) program, an acute general care program in the patients homes, the LOS will be added to the LOS on internal medicine wards.

\section{Secondary outcomes}

New diagnosis and change in management will be evaluated using forms about clinical assessment completed by the treating physician before and after the findings of POCUS are revealed to them. Both forms are exactly the same. The difference between them will be interpreted as the effect of the intervention. (Fig. 4).

The information requested in these forms includes (Additional file 2): 


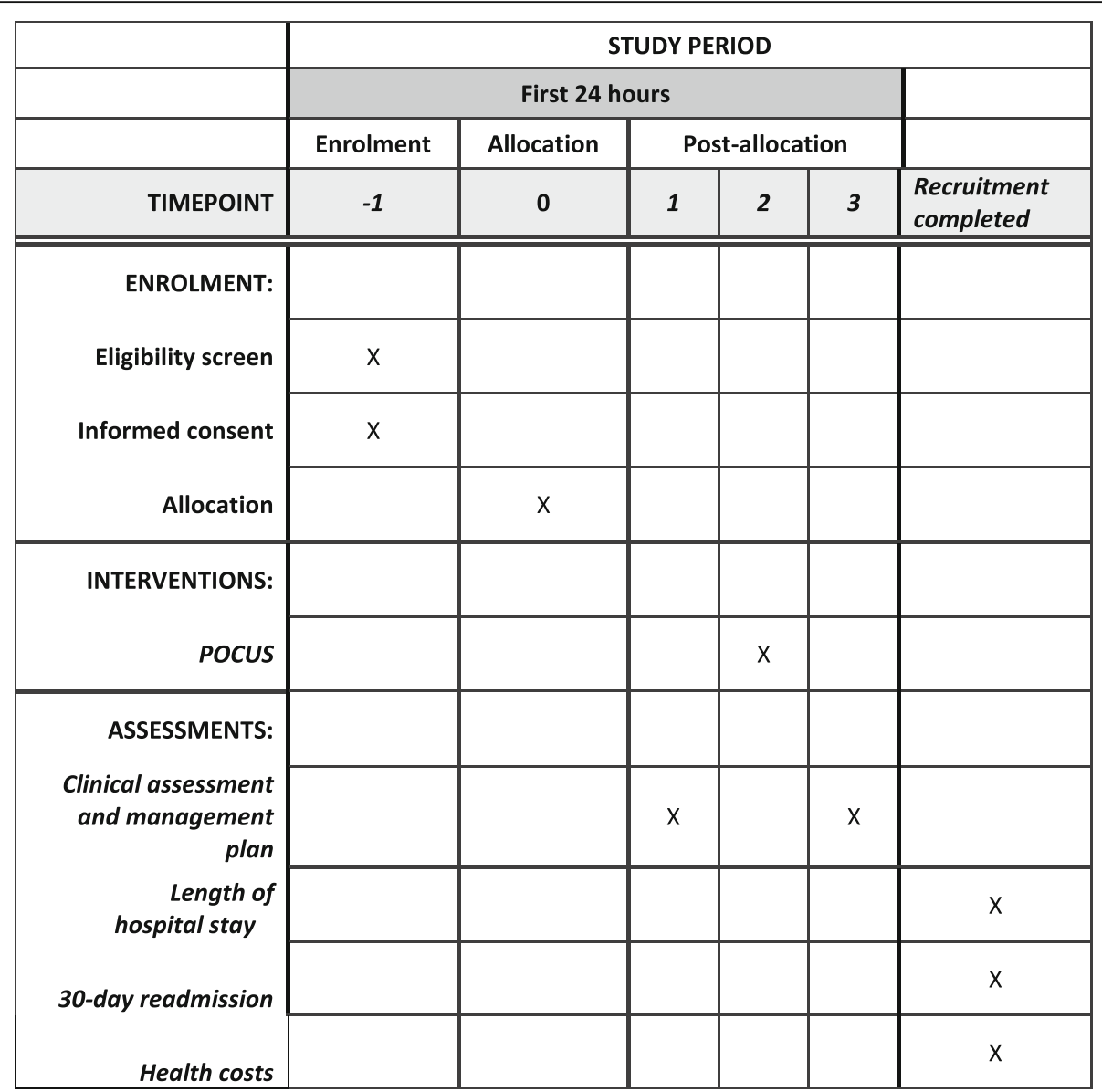

Fig. 5 Schedule of enrolment, intervention, and assessments

a. The hemodynamic state of the patients from the following options: normal; hypovolemia; primary diastolic failure; primary systolic failure; systolic and diastolic failure; vasodilation; and RV failure.

b. Describing physical examination findings specifying LV function, significant valve regurgitation or valve stenosis, pericardial effusion, suspicion of PE, abnormalities of the lungs, and evidence of DVT.

c. Recording the most likely diagnosis.

d. Detailing further investigations. In this section they will have a list of pathology tests, imaging tests, and consultations to other medical specialties. They will be asked to mark all the further investigations that they are requesting.

e. Describing the type of treatment prescribed from five options: (1) heart failure treatment (defined by one of the following treatment: diuretics, vasodilators, and/or fluid restriction); (2) COPD/ asthma treatment (defined as the use of bronchodilators and/or systemic steroids); (3) antibiotics; (4) anticoagulation in therapeutic dose; and (5) "other" in case it is a different treatment from the four above. More than one option can be chosen.

The seniority of doctors who will complete the forms is restricted to internal medicine specialists and specialist trainees.

Readmission to the hospital data will be gathered from hospital operating system in the same form that has been explained for the primary outcome. Planned readmissions will be excluded, analyzing only unplanned readmissions in the following 30 days after hospital discharge.

Information about economic health will be gathered directly from the Business Intelligence Unit. This unit centralizes all the information related to health costs and analyses it for administrative purposes.

Once the trial has finished recruiting, we will send them the blinded list of patients specifying the admission and discharge date. Hospital costs include total costs and categories such as bed stay, imaging tests, and pathology tests. 


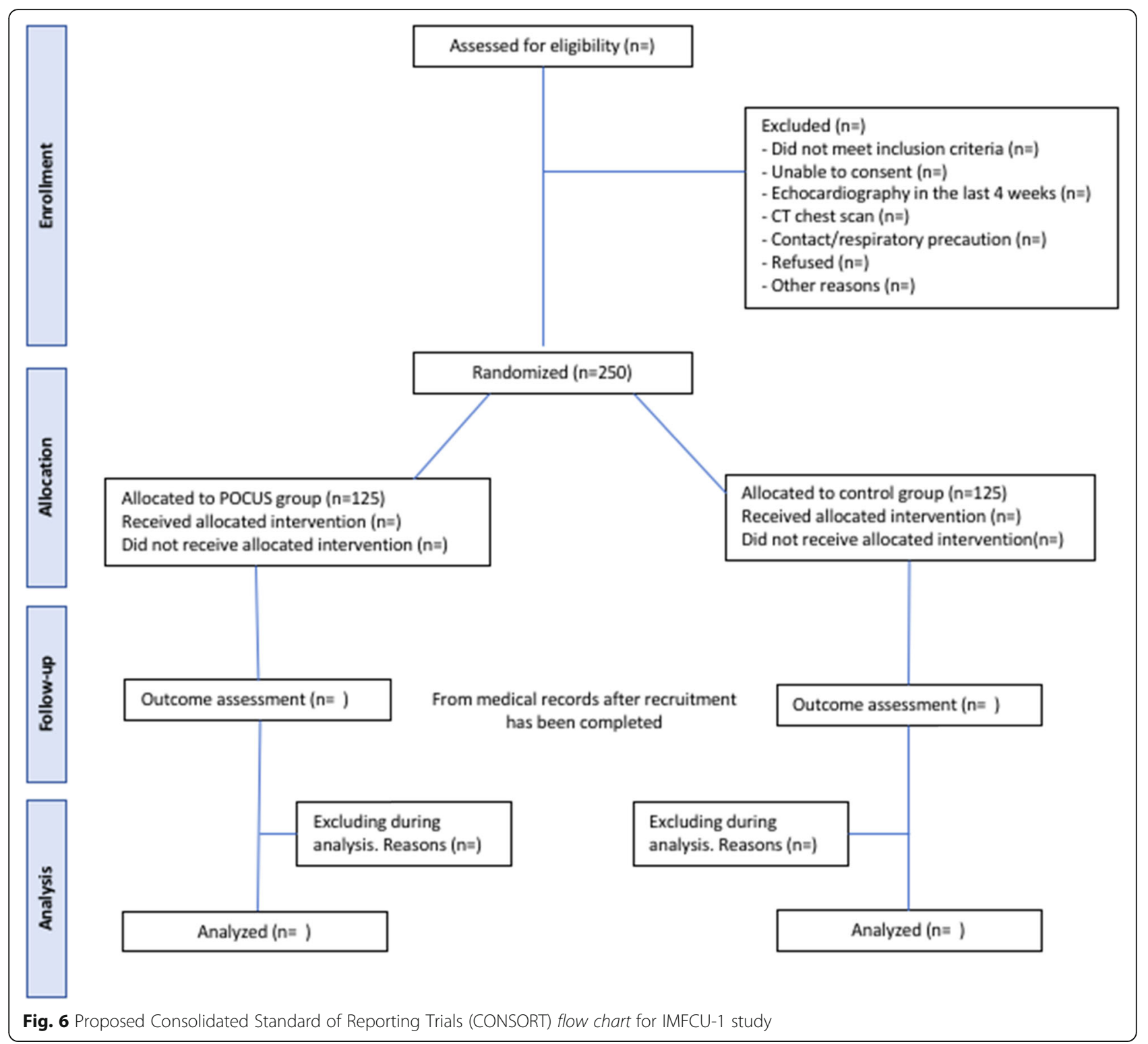

\section{Harms}

Performing POCUS is highly unlikely to cause unintended effects. It is a non-invasive and ionizing radiation-free imaging test with no severe side effects reported other than infrequent patient discomfort [50]. However, severe bruising from probe manipulation over the skin and patient falls during the procedure set-up (e.g. when a patient is transferred from the chair to their bed) will be documented and reported in the final results as total number of events. If any of these events occur, management will have to refer the event to the treating physician.

\section{Statistical methods}

The primary outcome, LOS in hours, will be analyzed using Student's t-test on the log scale, in anticipation of skewness in raw LOS. Log transforming might normalize a skewed data, making outliers unlikely. However, a cutoff of 30 days will be applied to LOS to avoid the effect of extremely long hospital stays. Statistical analysis will be done using the software SPPS (Statistical Package for the Social Sciences), version 26.

For patients who die in hospital, death will be treated as hospital discharge for the primary analysis as the unpublished mortality rate of patients admitted to internal medicine wards of the RMH is low $(2.7 \%)$. However, a sensitivity analysis will be conducted to explore the impact of this approach. Missing data for the primary outcome are not expected as it is anticipated that LOS will be available for every patient in the study. If for some reason this information is missing, those patients will not be included in the primary statistical analysis. 
Table 5 Patient basal data to be collected

\begin{tabular}{|c|c|}
\hline \multirow[t]{5}{*}{ Demographic data } & Age (years) \\
\hline & Gender (female) \\
\hline & Height $(\mathrm{cm})$ \\
\hline & Weight (kg) \\
\hline & $\mathrm{BMI}\left(\mathrm{kg} / \mathrm{m}^{2}\right)$ \\
\hline \multirow[t]{23}{*}{ Prior medical conditions } & Hypertension \\
\hline & Congestive cardiac failure \\
\hline & Angina \\
\hline & Myocardial infarction \\
\hline & Coronary intervention \\
\hline & Known significant valve disease \\
\hline & Valve replacement \\
\hline & Cardiac arrhythmia \\
\hline & Pulmonary hypertension \\
\hline & COPD \\
\hline & Interstitial lung disease \\
\hline & Asthma \\
\hline & Smoking \\
\hline & Diabetes \\
\hline & Known renal failure \\
\hline & Stroke \\
\hline & HIV \\
\hline & Venous thromboembolism \\
\hline & Cancer (type, active/remission, metastasis) \\
\hline & Chronic liver disease \\
\hline & Hypothyroidism \\
\hline & Hyperthyroidism \\
\hline & Cognitive impairment/dementia \\
\hline \multirow[t]{8}{*}{ Chronic medication } & Antihypertensive \\
\hline & Beta-blockers \\
\hline & Antiplatelet \\
\hline & Anticoagulant \\
\hline & Systemic steroids \\
\hline & Diuretics \\
\hline & Chemotherapy \\
\hline & Other \\
\hline \multirow{8}{*}{$\begin{array}{l}\text { Cardiopulmonary } \\
\text { symptoms }\end{array}$} & Dyspnea/shortness of breath \\
\hline & Chest pain \\
\hline & Palpitations \\
\hline & Cough \\
\hline & $\begin{array}{l}\text { Fever suspected to be respiratory or } \\
\text { cardiac }\end{array}$ \\
\hline & Lower limb edema \\
\hline & Altered state of consciousness \\
\hline & Other \\
\hline
\end{tabular}

Table 5 Patient basal data to be collected (Continued)

\begin{tabular}{ll}
\hline Vital signs & Blood pressure $(\mathrm{mmHg})$ \\
& Heart rate (beats per minute) \\
& Temperature $\left({ }^{\circ} \mathrm{C}\right)$ \\
& Respiratory rate (breaths per minute) \\
& $\mathrm{O}_{2}$ saturation $(\%)$ \\
\hline
\end{tabular}

$B M I$ body mass index, COPD chronic obstructive pulmonary disease, HIV human immunodeficiency virus

For the primary outcome, significance is defined as $p<0.05$. Secondary outcomes will be analyzed using parametric or non-parametric tests according to the type of data, whether the data are skewed, and whether repeated measures are used. As the secondary endpoints involve more pairwise comparisons, significance will be defined as $p<0.01$ to reduce the risk of Type 1 error from multiple pairwise comparisons. All estimates will be reported with $95 \%$ confidence intervals. All analysis will be based on the principle of intention-to-treat.

\section{Data management}

All data will be entered electronically using numerical codes. Paper records will be stored in files in a locked filing cabinet, in a locked room in the Department of Surgery of the University of Melbourne. Electronic data are stored in password-protected databases, available only to researchers involved in the study. The primary outcome and health cost data are generated from the hospital electronic systems and not under the influence of investigators. Other data will undergo double data entry range checks for data value errors.

Due to the small trial size, there is neither Data Monitoring Committee (DMC) established nor stopping rules applied. There is no planned interim analysis.

The final results of this study are intended to be disseminated through publications in peer-reviewed medical journals. After publishing, data about demographic, primary, and secondary outcomes will be shared to other researchers who request it to the principal investigator with a project proposal and with acceptance of release of data by the Melbourne Health Human Research Ethics Committee.

\section{Discussion}

This study will show whether the addition of a multiorgan POCUS in internal medicine patients reduces the LOS at the hospital. LOS was selected as the main outcome as it was considered objective, reliable data and clinically relevant to both the patient and the healthcare system. Demonstrating an impact in LOS will encourage physicians around the world to incorporate this technique in their routinely practice. 
The novelty of this study is that it is the first randomized trial assessing the impact on LOS of a multi-organ focused ultrasound in internal medicine. Last year, Mozzini et al. [51] described a positive impact of repetitive lung ultrasounds on the LOS in patients with heart failure admitted to the internal medicine ward. Based on their results, we are optimistic about finding a positive effect this time assessing a multi-organ focused ultrasound which not only evaluate lung but also heart and DVT.

The limitations of the study are that the outcomes are short-term and related to hospital admission. This study will provide clinical data that can serve to assess feasibility and sample size for a trial investigating morbidity and mortality outcomes. A randomized pilot study investigating focused cardiac ultrasound in patients undergoing fractured neck of femur surgery showed a group separation of 30-day mortality and morbidity outcomes of $39 \%$ favoring the use of cardiac ultrasound [52] and a lower 12-month mortality [53]. The sample size of this study, however, is too small to investigate morbidity and mortality outcomes for the cardiopulmonary admissions to internal medicine wards. Further, the use of ultrasound in not a medical intervention but rather an investigation. The behavior change consequent on the information is the actual mechanism whereby improved outcomes can occur. If the treating medical staff choose to ignore the findings, or not act appropriately upon them, then the value of the ultrasound examination is diminished. This problem is most likely to occur at the start of the study where skepticism regarding the POCUS study exists and reduces over time as the additional knowledge form a feedback loop on the clinician's diagnostic approach.

\section{Trial status}

Recruiting.

Recruitment began on 3 September 2018.

\section{Supplementary information}

Supplementary information accompanies this paper at https://doi.org/10. 1186/s13063-019-4003-2.

Additional file 1. SPIRIT 2013 Checklist: Recommended items to address in a clinical trial protocol and related documents.

Additional file 2. Clinical Assessment.

\section{Abbreviations}

A4C: Apical four chambers; COPD: Chronic obstructive pulmonary disease; DVT: Deep venous thrombosis; LA: Left atrium; LOS: Length of stay; LV: Left ventricle; LVEDA: Left ventricle end-diastole area; LVEDD: Left ventricle enddiastole diameter; LVESA: Left ventricle end-systole area; LVESD: Left ventricle end-systole diameter; PE: Pulmonary embolism; PLAX: Parasternal long axis; POCUS: Point-of-care ultrasound; PSAX: Parasternal short axis; RMH: Royal Melbourne Hospital; RV: Right ventricle; RVEDD: Right ventricle end-diastole diameter

\section{Acknowledgements}

We acknowledge Lynda Tivendale for her support and contribution to the trial. We also acknowledge the significant role of Internal Medicine staff and trainees of the Royal Melbourne Hospital, who have made this study possible; and Lacey Whelan who has helped us with the illustrations.

\section{Authors' contributions}

XC contributed to the trial protocol, performed patients screening and recruitment, performed ultrasound, contributed to data analysis and manuscript preparation and submission. CR contributed to the trial protocol and design, ultrasound review, analysis and interpretation of the data and manuscript preparation. AR and DC performed ultrasound review, contributed to analysis of the data, and manuscript preparation. DEA contributed to the protocol and preparation of manuscript. DJ and ABM contributed to the protocol and manuscript preparation. SCE performed the statistical design and analysis. TF assisted with data collection and analysis. All authors read and approved the final manuscript.

\section{Authors' information}

XC: Internal medicine specialist in Chile. Candidate for PhD of Medicine confirmed at the University of Melbourne, Australia.

CR: Professor in the Department of Surgery (Royal Melbourne Hospital), University of Melbourne. Consultant anesthetist in the Department of Anaesthesia and Pain Management of Royal Melbourne Hospital, Australia. AR: Professor in the Department of Surgery (Royal Melbourne Hospital), University of Melbourne. Consultant Cardiothoracic Surgeon in the Department of Cardiothoracic Surgery of the Royal Melbourne Hospital, Australia.

DC: Director of Ultrasound Simulation and Senior lecturer in the Department of Surgery (Royal Melbourne Hospital), University of Melbourne. Consultant anesthetist at Monash Medical Centre, Department of Medicine, Monash University Australia.

DJ: Associate Professor of the University of Melbourne. Consultant General Medicine and Infectious Disease physician. Head of the Service of General Medicine of the Royal Melbourne Hospital, Australia.

ABM: Professor of Medicine and Aged Care at the University of Melbourne and Professor of Ageing at the Vrije Universiteit, The Netherlands. Consultant Geriatrician and Internal Medicine. Divisional Director of the Department of Medicine and Community Care of the Royal Melbourne Hospital, Australia. DEA: Course Director of Physiotherapy and Director of Research

Development, Department of Health Professions, Faculty of Health, Arts and Design, Swinburne University of Technology. Senior Research Fellow, Department of Surgery, University of Melbourne.

SCE: Specialist statistician, Statistical Consulting, The University of Melbourne. TF: Consultant Physician in Metabolic Disease Unit. Clinical informatics lead at the Business Intelligence Unit. Deputy Chief Medical information officer. Royal Melbourne Hospital.

Funding

The trial does not have a funding body.

Consent for publication

Written consent was obtained from participants for publication of their individual data.

\section{Competing interests}

The authors declare that they have no competing interests.

\section{Author details}

'Department of Surgery, University of Melbourne, Melbourne, VIC, Australia. ${ }^{2}$ Department of Medicine and Community Care, Royal Melbourne Hospital, Parkville, VIC, Australia. ${ }^{3}$ Department of Anesthesia and Perioperative Medicine, Monash Health, Melbourne, VIC, Australia. ${ }^{4}$ Department of Anesthesia and Pain Management, Royal Melbourne Hospital, Parkville, VIC, Australia. ${ }^{5}$ Department of Surgery, Royal Melbourne Hospital, Parkville, VIC, Australia. ${ }^{6}$ Department of Medicine and Aged Care, @AgeMelbourne, The Royal Melbourne Hospital, University of Melbourne, Melbourne, VIC, Australia. ${ }^{7}$ Department of Human Movement Sciences, @AgeAmsterdam, Amsterdam Movement Sciences, Vrije Universitet, Amsterdam, The Netherlands. ${ }^{8}$ Department of Health Professions, Swinburne University of Technology, Melbourne, VIC, Australia. ${ }^{9}$ Statistical Consulting Centre, University of 
Melbourne, Parkville, VIC, Australia. ${ }^{10}$ Business Intelligence Unit, Melbourne Health, Parkville, VIC, Australia. "'Department of Medicine and Radiology, Melbourne Medical School, University of Melbourne, Parkville, VIC, Australia. ${ }^{12}$ Outcomes Consortium, Cleveland Clinic, Cleveland, OH, USA.

Received: 24 July 2019 Accepted: 16 December 2019 Published online: 08 January 2020

\section{References}

1. Spencer KT, Anderson AS, Bhargava A, Bales A, Sorrentino M, Furlong K, et al. Physician-performed point-of-care echocardiography using a laptop platform compared with physical examination in the cardiovascular patient. J Am Coll Cardiol. 2001;37(8):2013-8.

2. Cardim N, Fernandez C, Ferreira D, Aubele A, Toste J, Cobos MA, et al. Usefulness of a new miniaturized echocardiographic system in outpatient cardiology consultations as an extension of physical examination. J Am Soc Echocardiogr. 2011;24:117-24.

3. Panoulas VF, Daigeler AL, Malaweera AS, Lota AS, Baskaran D, Rahman S, et al. Pocket-size hand-held cardiac ultrasound as an adjunct to clinical examination in the hands of medical students and junior doctors. Eur Heart J Cardiovasc Imaging. 2013;14(4):323-30.

4. Galderisi M, Santoro A, Versiero M, Lomoriello VS, Esposito R, Raia R, et al. Improved cardiovascular diagnostic accuracy by pocket size imaging device in non-cardiologic outpatients: the NaUSiCa (Naples Ultrasound Stethoscope in Cardiology) study. Cardiovasc Ultrasound. 2010;8:51.

5. Bhagra A, Tierney DM, Sekiguchi $H$, Soni NJ. Point-of-care ultrasonography for primary care physicians and general internists. Mayo Clin Proc. 2016; 91(12):1811-27.

6. Lucas BP, Candotti C, Margeta B, Evans AT, Mba B, Baru J, et al. Diagnostic accuracy of hospitalist-performed hand-carried ultrasound echocardiography after a brief training program. J Hosp Med. 2009;4(6):340-9.

7. Johnson BK, Tierney DM, Rosborough TK, Harris KM, Newell MC. Internal medicine point-of-care ultrasound assessment of left ventricular function correlates with formal echocardiograpy. J Clin Ultrasound. 2016:44:92-9.

8. Amiel JB, Grumann A, Lheritier G, Clavel M, Francois B, Pichon N, et al. Assessment of left ventricular ejection fraction using an ultrasonic stethoscope in critically ill patients. Crit Care. 2012;16(1):R29.

9. Torres-Macho J, Anton-Santos JM, Garcia-Gutierrez I, de Castro-Garcia M, Gamez-Diez S, de la Torre PG, et al. Initial accuracy of bedside ultrasound performed by emergency physicians for multiple indications after a short training period. Am J Emerg Med. 2012;30(9):1943-9.

10. Al Deeb M, Barbic S, Featherstone R, Dankoff J, Barbic D. Point-of-care ultrasonography for the diagnosis of acute cardiogenic pulmonary edema in patients presenting with acute dyspnea: a systematic review and metaanalysis. Acad Emerg Med. 2014;21(8):843-52.

11. Grimberg A, Shigueoka DC, Atallah AN, Ajzen S, lared W. Diagnostic accuracy of sonography for pleural effusion: systematic review. Sao Paulo Med J. 2010;128(2):90-5.

12. Pomero F, Dentali F, Borretta V, Bonzini M, Melchio R, Douketis JD, et al. Accuracy of emergency physician-performed ultrasonography in the diagnosis of deep-vein thrombosis: a systematic review and meta-analysis. Thromb Haemost. 2013;109(1):137-45.

13. Ding W, Shen Y, Yang J, He X, Zhang M. Diagnosis of pneumothorax by radiography and ultrasonography: a meta-analysis. Chest. 2011;140(4):859-66.

14. Chavez MA, Shams N, Ellington LE, Naithani N, Gilman RH, Steinhoff MC, et al. Lung ultrasound for the diagnosis of pneumonia in adults: a systematic review and meta-analysis. Respir Res. 2014;15:50.

15. Royse CF. Ultrasound-guided haemodynamic state assessment. Best Pract Res Clin Anaesthesiol. 2009;23(3):273-83.

16. Shokoohi H, Boniface KS, Pourmand A, Liu YT, Davison DL, Hawkins KD, et al. Bedside ultrasound reduces diagnostic uncertainty and guides resuscitation in patients with undifferentiated hypotension. Crit Care Med. 2015:43(12):2562-9.

17. Heiberg J, El-Ansary D, Canty DJ, Royse AG, Royse CF. Focused echocardiography: a systemic review of diagnostic and clinical decisionmaking in anaesthesia and critical care. Anaesthesia. 2016;71:1091-100.

18. Haji DL, Royse A, Royse C. Review article: Clinical impact of noncardiologist-performed transthoracic echocardiography in emergency medicine, intensive care medicine and anaesthesia. Emerg Med Australas. 2013;25:4-12.
19. Whitson MR, Mayo PH. Ultrasonography in the emergency department. Crit Care. 2016;20(1):227.

20. Bainbridge D, McConnell B, Royse C. A review of diagnostic accuracy and clinical impact from the focused use of perioperative ultrasound. Can J Anaesth. 2018;65(4):371-80.

21. Faris JG, Veltman MG, Royse C. Focused transthoracic echocardiography in the perioperative period. Anaesth Intensive Care. 2011;39(2):306-7 author reply $7-8$.

22. Xirouchaki N, Magkanas E, Vaporidi K, Kondili E, Plataki M, Patrianakos A, et al. Lung ultrasound in critically ill patients: comparison with bedside chest radiography. Intensive Care Med. 2011;37(9):1488-93.

23. Bourcier JE, Paquet J, Seinger M, Gallard E, Redonnet JP, Cheddadi F, et al. Performance comparison of lung ultrasound and chest $x$-ray for the diagnosis of pneumonia in the ED. Am J Emerg Med. 2014;32(2):115-8.

24. Mantuani D, Frazee BW, Fahimi J, Nagdev A. Point-of-care multi-organ ultrasound improves diagnostic accuracy in adults presenting to the emergency department with acute dyspnea. West J Emerg Med. 2016;17(1):46-53.

25. Zanobetti M, Scorpiniti M, Gigli C, Nazerian P, Vanni S, Innocenti F, et al. Point-of-care ultrasonography for evaluation of acute dyspnea in the ED. Chest. 2017;151(6):1295-301.

26. Sforza A, Mancusi C, Carlino MV, Buonauro A, Barozzi M, Romano G, et al. Diagnostic performance of multi-organ ultrasound with pocket-sized device in the management of acute dyspnea. Cardiovasc Ultrasound. 2017;15(1):16.

27. Laursen CB, Sloth E, Lassen AT, Christensen R, Lambrechtsen J, Madsen PH, et al. Point-of-care ultrasonography in patients admitted with respiratory symptoms: a single-blind, randomised controlled trial. Lancet Respir Med. 2014;2(8):638-46.

28. Perrone T, Maggi A, Sgarlata C, Palumbo I, Mossolani E, Ferrari S, et al. Lung ultrasound in internal medicine: A bedside help to increase accuracy in the diagnosis of dyspnea. Eur J Intern Med. 2017;46:61-5.

29. Pivetta E, Goffi A, Lupia E, Tizzani M, Porrino G, Ferreri E, et al. Lung ultrasound-implemented diagnosis of acute decompensated heart failure in the ED: A SIMEU Multicenter Study. Chest. 2015;148(1):202-10.

30. Vizioli L, Forti P, Bartoli E, Giovagnoli M, Recinella G, Bernucci D, et al. Accuracy of lung ultrasound in patients with acute dyspnea: the influence of age, multimorbidity and cognitive and motor impairment. Ultrasound Med Biol. 2017:43(9):1846-52.

31. Vitturi N, Soattin M, Allemand E, Simoni F, Realdi G. Thoracic ultrasonography: A new method for the work-up of patients with dyspnea(). J Ultrasound. 2011;14(3):147-51.

32. Filopei J, Siedenburg H, Rattner P, Fukaya E, Kory P. Impact of pocket ultrasound use by internal medicine housestaff in the diagnosis of dyspnea. J Hosp Med. 2014;9(9):594-7.

33. Gallard E, Redonnet JP, Bourcier JE, Deshaies D, Largeteau N, Amalric JM, et al. Diagnostic performance of cardiopulmonary ultrasound performed by the emergency physician in the management of acute dyspnea. Am J Emerg Med. 2015;33(3):352-8.

34. Kajimoto K, Madeen K, Nakayama T, Tsudo H, Kuroda T, Abe T. Rapid evaluation by lung-cardiac-inferior vena cava $(\mathrm{LCl})$ integrated ultrasound for differentiating heart failure from pulmonary disease as the cause of acute dyspnea in the emergency setting. Cardiovasc Ultrasound. 2012;10(1):49.

35. Yates J, Royse CF, Royse C, Royse AG, Canty DJ. Focused cardiac ultrasound is feasible in the general practice setting and alters diagnosis and management of cardiac disease. Echo Res Pract. 2016;3(3):63-9.

36. Andersen GN, Graven T, Skjetne K, Mjolstad OC, Kleinau JO, Olsen O, et al. Diagnostic influence of routine point-of-care pocket-size ultrasound examinations performed by medical residents. J Ultrasound Med. 2015:34(4):627-36.

37. Breitkreutz R, Price S, Steiger HV, Seeger FH, Ilper H, Ackermann H, et al. Focused echocardiographic evaluation in life support and peri-resuscitation of emergency patients: a prospective trial. Resuscitation. 2010;81(11):1527-33.

38. Sasmaz Ml, Gungor F, Guven R, Akyol KC, Kozaci N, Kesapli M. Effect of focused bedside ultrasonography in hypotensive patients on the clinical decision of emergency physicians. Emerg Med Int. 2017;2017:6248687.

39. Marcelino P, Marques S, Matos AP, Germano N, Lopes M. Routine transthoracic echocardiography in general Intensive Care Unit: An 18 month survey in 704 patients. Eur J Intern Med. 2009;20:e37-42.

40. Croft LB, Duvall WL, Goldman ME. A pilot study of the clinical impact of hand-carried cardiac ultrasound in the medical clinic. Echocardiography. 2006;23(6):439-46 
41. Caronia J, Panagopoulos G, Devita M, Tofighi B, Mahdavi R, Levin B, et al. Focused renal sonography performed and interpreted by internal medicine residents. J Ultrasound Med. 2013;32(11):2007-12.

42. Crisp JG, Lovato LM, Jang TB. Compression ultrasonography of the lower extremity with portable vascular ultrasonography can accurately detect deep venous thrombosis in the emergency department. Ann Emerg Med. 2010;56(6):601-10.

43. Beltran LM, Garcia-Casasola G, members of the Group of Clinical Ultrasound of the Spanish Society of Internal M. Ultrasonography managed by internists: the stethoscope of 21st century? Rev Clin Esp (Barc). 2014;214(3):155-60.

44. Berliner D, Schneider N, Welte T, Bauersachs J. The Differential Diagnosis of Dyspnea. Dtsch Arztebl Int. 2016;113(49):834-45.

45. Adhikari S, Zeger W, Thom C, Fields JM. Isolated deep venous thrombosis: implications for 2-point compression ultrasonography of the lower extremity. Ann Emerg Med. 2015;66(3):262-6.

46. Chan AW, Tetzlaff JM, Gotzsche PC, Altman DG, Mann H, Berlin JA, et al. SPIRIT 2013 explanation and elaboration: guidance for protocols of clinical trials. BMJ. 2013;346:e7586.

47. Royse CF, Haji DL, Faris JG, Veltman MG, Kumar A, Royse AG. Evaluation of the interpretative skills of participants of a limited transthoracic echocardiography training course (H.A.R.T.scan course). Anaesth Intensive Care. 2012:40(3):498-504

48. Royse CF, Royse AG, Bharatula A, Lai J, Veltman M, Cope L, et al. Substernal epicardial echocardiography: a recommended examination sequence and clinical evaluation in patients undergoing cardiac surgery. Ann Thorac Surg. 2004;78(2):613-9 discussion 9.

49. Ford JW, Heiberg J, Brennan AP, Royse CF, Canty DJ, El-Ansary D, et al. A pilot assessment of 3 point-of-care strategies for diagnosis of perioperative lung pathology. Anesth Analg. 2017;124(3):734-42.

50. Laursen CB, Sloth E, Lassen AT, Davidsen JR, Lambrechtsen J, Henriksen DP, et al. Does point-of-care ultrasonography cause discomfort in patients admitted with respiratory symptoms? Scand I Trauma Resusc Emerg Med. 2015;23:46.

51. Mozzini C, Di Dio PM, Pesce G, Garbin U, Fratta Pasini AM, Ticinesi A, et al. Lung ultrasound in internal medicine efficiently drives the management of patients with heart failure and speeds up the discharge time. Intern Emerg Med. 2018;13(1):27-33

52. Canty DJ, Heiberg J, Yang Y, Royse AG, Margale S, Nanjappa N, et al. Pilot multi-centre randomised trial of the impact of pre-operative focused cardiac ultrasound on mortality and morbidity in patients having surgery for femoral neck fractures (ECHONOF-2 pilot). Anaesthesia. 2018;73(4):428-37.

53. Canty DJ, Heiberg J, Yang Y, Royse AG, Margale S, Nanjappa N, et al. Oneyear results of the pilot multicentre randomised trial of preoperative focused cardiac ultrasound in hip fracture surgery. Anaesth Intensive Care. 2019;47:207-8

\section{Publisher's Note}

Springer Nature remains neutral with regard to jurisdictional claims in published maps and institutional affiliations.

Ready to submit your research? Choose BMC and benefit from:

- fast, convenient online submission

- thorough peer review by experienced researchers in your field

- rapid publication on acceptance

- support for research data, including large and complex data types

- gold Open Access which fosters wider collaboration and increased citations

- maximum visibility for your research: over $100 \mathrm{M}$ website views per year

At BMC, research is always in progress.

Learn more biomedcentral.com/submissions 